\title{
RESENHA
}

\section{(RE) CONHECENDO OS SUJEITOS DA EJA: docentes-educadores e educandos em formação política e pedagógica resistentes na luta por uma vida justa}

Debora dos Reis Cordeiro Arrudal

Talita de Jesus da Silva Martins²

ARROYO, Miguel G. Passageiros da Noite - do trabalho para a EJA: itinerários pelo direito a uma vida justa. - Petrópolis, RJ: Vozes, 2017. 294 p. ISBN: 978-85326-5509-7.

Indaga Miguel Arroyo (2017): quais os rumos da Educação de Jovens e Adultos (EJA) se continuarmos a pensar os seus sujeitos fora do circuito pedagógico dessa modalidade/nível educativa? Quem são, afinal, esses sujeitos que se deslocam pelas cidades e campos, num trajeto trabalhoestudo diariamente? $\mathrm{O}$ que perseguem, pretendem e como se veem nesse processo? $\bigcirc$ que trazem na bagagem? Quais suas identidades coletivas de classe, gênero, sexo? E, principalmente, qual tomada de ação será desprendida face a essas respostas que virão quando, enfim, forem ouvidas?

Diversos questionamentos surgem como norteadores dos textos arrolados em "Passageiros da noite: do trabalho para a EJA - itinerários pelo direito a uma vida justa", de 294 p.; tais questões são os norteamentos para a construção do pensamento do autor que, mediante metodologia de estudo baseada na dialética histórico-crítica, perfaz um caminho preciso de pôr em suspenso à educação sistêmica para os que estão à margem do sistema. Objetiva, destarte, captar a soma das experiências dos sujeitos envolvidos na EJA, possibilitando delimitar os conhecimentos próprios da identidade coletiva desses que sugerem uma pedagogia radical, a saber, a que milita na fronteira da humanização-desumanização. Para tanto, Arroyo agrupa

\footnotetext{
1 Mestra em Dinâmicas Territoriais e Sociedade na Amazônia (Unifesspa). Professora de PósGraduação pelo Instituto Universidade Atlântica (IUA). E-mail: dborareis@hotmail.com

2 Mestra em Educação (UFMA). Professora do Departamento de Educação II da Universidade Federal do Maranhão. E-mail: talita.martins@ufma.com
} 
dez temas geradores possíveis de serem tratados nesse processo, que surgem, indubitavelmente, de questionamentos pertinentes à realidade dos educandos e educadores.

A primeira seção intitulada "Passageiros - em que passagens humanas?", traz consigo duas indagações de imediato: de onde e para onde? Há nessa indagação a urgência de entendermos os caminhositinerários dos passageiros da EJA. Debruça-se, assim, nos pontos de ônibus repletos de passageiros em filas, ao entardecer - saindo de trabalhos precarizados em "bairros-bens" - e à noite, voltando para casa em bairros à margem da "civilização". Ao se reunirem, aglutinam-se em suas semelhanças: trabalhadores, mulheres, negros, pobres; emerge compreender quais as identidades coletivas desse público, qual território sócio-espacial ocupam, haja vista que essas minorias precisam ser reconhecidas e precisam se reconhecer em sua "cartografia social", se ver nos trajetos entre as partidas e chegadas e como ocupam esses espaços nos quais transitam.

Na segunda seção "Do trabalho para a EJA - de que trabalhos?" o debate desafia a lógica assistencialista e desenvolvimentista que buscam suprir as "debilidades" e "atrasos" epistêmicos dos educandos para, enfim, serem recolocados - em um futuro não palpável - dignamente em sociedade, visionado um mercado de trabalho mais "promissor". O autor refuta essa possibilidade para a EJA atual, não defende, doutro modo, que não estejam selecionados conhecimentos possíveis para se alcançar níveis com maior grau de competência no mundo do trabalho, entretanto, vê como urgente a construção de uma educação onde o educando/educador possa compreender como se manter/sobreviver/resistir hoje. O ato de "des-romantizar" o currículo da EJA é necessário para que outro pensamento acerca do trabalho e trabalhador surja. É imprescindível trazer o trabalho e o trabalhador para a EJA e para a formação de educadores, aprofundando-se nos conhecimentos e nas correlações de poder sócio-política do trabalho nos quais estão se forjando, a fim de não 
somente produzirem, mas de entenderem toda a dinâmica de produção/exploração do trabalho/trabalhador.

Ver a realidade laboral dos discentes, na lógica de uma educação humanizadora é um duplo avanço ao passo que valoriza quais expertises e (poli) técnicas tais atores estão desenvolvendo nesses trabalhos não formais (precarizados, subempregados) e, em consequência disso, permite uma docência/currículo ricos de saberes reais que são capazes de instrumentalizar o trabalhador para se organizar coletivamente rumo ao combate às injustiças. Nesse sentido, Arroyo destaca que é importante observar os movimentos dos trabalhadores em suas organizações políticas, como partícipes da luta pelo direito à educação, e consequentemente, por cidadania.

A terceira seção, que se desenvolve no entendimento "Do trabalho e das lutas e das lutas do Campo", ratifica esse envolvimento citado anteriormente. Trata da recente história da Educação do Campo na dinâmica do engajamento político do direito à educação com o direito ao trabalho e à cidadania. O autor situa que foram os movimentos sociais dos trabalhadores do campo que, em posição de luta e resistência, pleitearam por uma educação digna e humana, longe dos circuitos pedagógicos homogeneizantes e excludentes da educação rural, pensada para subalternizar tais povos.

Na quarta e quinta seção, "Direito a uma vida justa" e "Sujeitos coletivos de direito", Arroyo compreende que os sujeitos discentes-docentes ao verem a EJA como a última instância para reparar os danos de uma marginalização, despercebem que é também no sistema escolar que se constroem fossos da desigualdade social; a relação entre educação e justiça, desse modo, torna-se complexa, necessitando a escola e a EJA tomar emprestado o mesmo modus operandi dos movimentos sociais, que é o de alinhar a resistência à ética, à justiça e por fim, à educação, conduzindo o oprimido a narrar suas experiências de exclusão, ampliando a noção dessa opressão nas estruturas sociopolíticas e, por fim, costurando uma relação pedagógica que supere tais obstáculos à justiça humana. 
Esse resgate da centralidade das lutas pelos direitos humanos acarreta uma formação humana que mitiga os efeitos negativos das imagens sociais construídas desses jovens-adultos. Esses saberes de si permitem mais que uma autoanálise, são, na verdade, conhecimentos críticos que thes situam em outra identidade, a coletiva, mais amadurecida, que impulsiona a EJA a encontrar outros motivadores que não o crescimento individualizado de seus atores, à medida que se afirmam como sujeitos coletivos de direitos; o indivíduo numa escalada cultural, econômica cede lugar à luta do grupo, reunindo tais atores por suas singularidades, sobretudo a política, que se fundamenta na medida que os educandos, independentemente de suas diversidades, são reconhecidos como "Sujeitos do direito ao conhecimento", tema gerador da sexta seção.

Arroyo discute, na seção citada, o direito fundamental ao conhecimento como base prioritária para o pleno exercício da cidadania. Enfatizando-o como uma produção histórica, social, política e cultural que nos faz conhecedores das dinâmicas de exclusão às quais os jovensadolescentes e adultos da EJA são submetidos e, consequentemente, traz bases políticas para a formação e prática pedagógica dos seus docenteseducadores, reflexões sobre o currículo "território privilegiado de disputas" e do material didático visando à superação da segregação e desigualdade cidadã. Afirma, assim, que o direto a conhecer os processos de produção do conhecimento abre possibilidades a saberem-se, reconhecerem-se como pluralidade e diversidade de produtores de conhecimento dentro e fora das escolas, da EJA; a superar o padrão único de conhecimento que rouba sua humanidade, sua identidade e teima em legitimar sua condição de segregados sociais e escolares; a possibilitar o direito aos saberes do justo e digno viver cotidiano, enquanto luta de coletivos, enquanto luta sociais que são refletidas nas tensões vividas na escola.

No reconhecimento da complexidade do exercício do direito à educação, Arroyo nos traz como tema gerador na sétima seção "Sujeitos do direito à cultura, direito à diversidade" no qual discute a necessidade de se aprofundar os estreitos vínculos entre conhecimento, ciência e cultura como 
ação política e pedagógica na formação dos docentes-educadores, os formando como agentes profissionais do direito à cultura, e como prática cotidiana nas escolas, na EJA. Enfatiza a necessidades de serem abertos espaços para os jovens-adolescentes e adultos da EJA mostrarem-se como sujeitos de cultura, aprofundando o conhecimento sobre os valores e culturas que atuam como justificativa para segregá-los enquanto sem-terra, sem teto, sem trabalho, sem renda e, consequentemente, sem direito ao conhecimento ou a um conhecimento com instruções mínimas. Nessa perspectiva, o direito à cultura se faz intrínseco ao direito à diversidade resistente, ou seja, deve-se pensá-la como direito à formação humana que exige trabalhar questões históricas reais.

O direito ao conhecimento também exige o direito à memória, assim "Sujeitos do direito à memória, humanas memórias" é a oitava seção que problematiza sobre a construção da memória positiva e a consequente desconstrução da memória negativa em sua dimensão política, como ato de libertação. A reconstrução da memória positiva é uma forma de saberem-se na realidade pessoal, coletiva e social; é a afirmação de identidade de classe, de raça, de gênero. O direito à educação como direito à memória, às humanas memórias, devem ir além de um uso moralizante dos exemplos passados. Mais uma vez Arroyo preconiza aprender com os movimentos sociais, dessa vez mediante exploração dos significados políticos e emancipadores dos resgates de suas memórias coletivas que se interligam a memórias individuais, como ação política e pedagógica de reconhecimento dos valores coletivos; o resgate de memórias negativas não é fácil à pedagogia, pois se constitui como um reviver de dores ao mexer com a humilhação e segregação histórica, mas se faz ético na luta por uma vida justa, alerta Arroyo.

Na seção seguinte, abre-se diálogo acerca do "Aprender com os estudos da juventude", centrando-se sobre o desenvolvimento de estudos sobre juventude, que evidencia a condição juvenil como construção histórica e plural, constituindo-se como contribuição fundamental para a formação de jovens-adolescentes e adultos e seus docentes-educadores. 
Enquanto sujeitos de valores, identidades e saberes, a juventude deve ser reconhecida como produtora de culturas, de múltiplas identidades que deve pautar a prática docente, o material didático e transformar o currículo. "Outros sujeitos, outras pedagogias". Assim, reconhecer a condição juvenil é se aproximar do medo e da coragem que marcam a trajetória desses sujeitos, coragem como resistência, de se afirmarem enquanto detentores do direito ao conhecimento, coragem para voltar à escola.

Por fim, os sujeitos da EJA são reconhecidos enquanto "Totalidades humanas corpóreas". Partindo desse último tema gerador, Arroyo amplia o sentido do direito a educação ao trazer os corpos, tema ainda estranho para o debate pedagógico. Trata-se de tensões sobre imagens que fazem dos seus corpos, como são vistos, pensados e tratados, enquanto trabalhadores, mulheres, negros, indígenas, velhos e deficientes em uma sociedade marcada pela ditadura da beleza que segue as leis do mercado. Enfatiza a relação corpo, beleza e identidade enquanto tema para ações políticas-pedagógicas de todo profissional da educação comprometido com a formação humana. Nesse sentido, uma pedagogia dos corpos se faz necessária e urgente no processo de reconhecimento na estreita e tensa relação entre corporeidade, identidade, formação e humanização.

Levando-se em conta os pontos principais da obra em questão, devidamente destacados nas análises, é mister a compreensão de uma pedagogia capaz de resgatar, mediante pensamento crítico, uma Educação (repolitizada), que humaniza, distanciando-se do apartheid social-espacial. Tendo como eixo norteador a vida e o trabalho do adolescente, jovem e adulto, a educação não será apenas o meio para um futuro, mas o próprio hoje, possibilitando à relação pedagógica de se constituir como espaço aberto, flexível e contextualizado para esses sujeitos saberem-se vivos, saberem-se com direito à vida, saberem-se plurais em suas lutas, em suas resistências, saberem-se livres.

Recebida em: Abril de 2018 Aprovada em: Julho de 2018 